\title{
FUTURE INTELLIGENT EARTH OBSERVING SATELLITES
}

\author{
Guoqing Zhou ${ }^{1}$ and Menas Kafatos ${ }^{2}$ \\ ${ }^{1}$ Department of Civil Engineering and Technology, Old Dominion University, Kaufman Hall, Rm. 214, Norfolk, VA 23529 \\ Tel: (757) 683-3619; Fax: (757) 683-5655; E-mail: gzhou@ odu.edu \\ ${ }^{2}$ Center for Earth Observing and Space, George Mason University, Fairfax, VA 22030, USA
}

ISPRS Special Session, FIEOS/ISPRS

KEY WORDS: Intelligence, Earth Observing Satellite, Information Technology, Satellite Network, Sensor web

\begin{abstract}
This paper presents a simulated design of an envisioned future intelligent Earth observing satellite system (FIEOS). The proposed system is a space-based architecture for dynamic and comprehensive on-board integration of Earth observing sensors, data processors and communication systems. It is intended to enable simultaneous, global measurements and timely analyses of Earth's environment for a variety of users. The implementation strategies suggest a seamless integration of diverse components into a smart, adaptable, and robust Earth observation satellite system. The simulated design envisions a system that uses instruments capable of providing earth science measurements to a degree of precision and span of coverage not currently available. Common users would access data directly in a manner similar to selecting a TV channel. The imagery viewed would most likely be obtained directly from the satellite system. Real-time information systems are key to solving the challenges associated with this architecture. Realization of such a technologically complex system will require the contributions of scientists and engineers from many disciplines. Hopefully, this concept will impact how Earth observing satellite scientists conduct missions in decades to come.
\end{abstract}

\section{INTRODUCTION}

\subsection{Background}

In 1995, a conference titled "Land Earth Satellite for Decade" was sponsored by the American Society for Photogrammetry and Remote Sensing (ASPRS) and co-sponsored by the Landsat Management Team (NASA, NOAA, and USGS), NIMA, USDA, EPA, and others to address the future of Earth observing satellites. More than 700 experts from the satellite companies, value-added producers, and end-user communities took part in the conference to discuss anticipated applications, potential problems, and common solutions (Stoney, 1996). From the conference we concluded that the next generation of highresolution, multi(hyper)spectral satellite systems would be marketed and applied to a wide variety of Earth sciences. This prediction has come to pass as demonstrated by the 32 satellites at ground resolution from 1 to $15 \mathrm{~m}$ in panchromatic, multispectral and radar formats currently programmed to be in orbit by 2005 (Zhou, 2001a, 2001b). What is the "NEXT" generation of Earth Observing Satellites?

Since the beginning of space science in the 1960s, satellite remote sensing has been recognized as a valuable tool for viewing, analyzing, characterizing and making decisions about our environment. To meet the needs of different users for remotely sensed data, there are many systems offering a range of spatial, spectral, and temporal parameters. With the development of information technology, users' needs have migrated from traditional image-based data to advanced imagebased information/knowledge (Zhou, 2001). To meet these needs, the design of EO satellites is facing dramatic challenges. This paper describes our vision and simulated design for the Future Intelligent Earth Observing Satellites (FIEOS).

\subsection{History of Earth Observing Satellite Development}

It is difficult to divide the history of Earth observing satellite development into specific stages, but in a general sense there are four general phases (Figure 1). Note that few military (except de-classified) or meteorological satellites are included here. This is because (1) the parameters of many military satellites are hard to obtain and (2) meteorological satellites consist of numerous satellites measuring a wide variety of Earth variables.

\subsubsection{The First Generation: early 1960s thru 1972}

CORONA, ARGON and LANYARD were the first three operational satellite imaging reconnaissance systems. They acquired data for detailed reconnaissance purposes and for regional mapping. They were operated in response to the uncertainties and anxieties created by the Cold War (McDonald, 1995). The images derived from these early satellites consist of hundreds of thousands of photographs (some scanned and digitized), mostly black and white, but some in color and stereo, over large portions of Earth at resolutions of about $140 \mathrm{~m}$ (KH-5 camera, http://www.fas.org/spp/military/ program/imint/ corona.htm). The imagery, while highly instructive, was less systematic than later Landsat data. Primary characteristics of observation systems in these satellites were their imaging systems, which were basically aerial photogrammetric configurations (Zhou and Jezek, 2001a). For example, the ARGON 9034A mission, launched on May 16, 1962, carried a single panchromatic frame/film camera (KH-5) with a focal length of 3 inches. The overlap percentage of the neighboring photograph was $70 \%$. The gound resolution was $140 \mathrm{~m}$ with a ground swath of $556 \mathrm{~km}$ by $556 \mathrm{~km}$. Flying height was nominally $322 \mathrm{~km}$ with an inclination of $82.3^{\circ}$.

\subsubsection{The Second Generation: 1972 thru 1986}

Landsat 1, hunched on July 23, 1972, symbolized the modern era of Earth remote sensing (Lauer et al., 1997). For the first time it provided a consistent set of synoptic, high resolution Earth images to the world scientific community, and made it possible for the earth science community to use satellites for earth resource investigation (NASA, Landsate Satellites: Unique National Assets).The dominant characteristics of Landsat 1 were its multiple spectral scanner, which sensed four regions of

\section{FUTURE INTELLIGENT EARTH OBSERVINGSATELLITES}


the dectromagnetic spectrum between 0.5 and 1.1 microns, a reasonably high spatial resolution $(80 \mathrm{~m})$, a swath width of 185 $\mathrm{km}$, and repeat coverage every 18 days. Moreover, satellite image data were delivered directly in digital form for the first time. Much of the foundations of multispectral data processing were developed in the 1970s by organizations, such as NASA, the Jet Propulsion Laboratory (JPL), the U. S. Geological Survey (USGS), the Environmental Research Institute of Michigan (ERIM), and the Laboratory for Applications of Remote Sensing (LARS) at Purdue University. After 10 years, we have seen, in addition to four MSS bands, the Landsat Thematic Mapper (TM) in 1982 and 1984 with $30 \mathrm{~m}$ spatial resolution and 7 spectral bands, until the SPOT HRV in 1986 with $10 \mathrm{~m}$ resolution at panchromatic band and $30 \mathrm{~m}$ spatial resolution in 3 spectral bands.

\subsubsection{The Third Generation: 1986 thru 1997}

The EOS family experienced significant development in technologies and applications in the decade following 1986. The SPOT-1 satellite, launched on 22 February 1986 and carrying two High Resolution Visible ( $\underline{\mathrm{HRV}}$ ) sensors, was another benchmark because it was the first to use a linear array sensor with "push-broom" imaging geometry. With its $10 \mathrm{~m}$ panchromatic band it was the first satellite capable of stereoscopic imagery in cross-track. The ERS-1 Synthetic Aperture Radar (SAR), launched 17 July 1991 by the European Space Agency (ESA), is an active microwave sensor satellite with $30 \mathrm{~m}$ spatial resolution in imaging mode. The Japanese ERS-1, launched in February 1992, added more breadth to SAR applications by adding an L-band to the configuration. These active microwave sensors provide data useful primarily for improving the understanding of environmental and climate phenomena, as well as supporting a variety of operational applications such as sea-ice charting and coastal zone studies.

\subsubsection{The Fourth Generation: 1997 to "2010"}

Specifications for the latest generation of satellites vary widely. Their major features are high spatial and/or temporal resolution, , spectral coverage, orbital altitude, revisit capability, width of swath, stereo capability, multiple imaging modes, data record, satellite ownership and market requirements. A detailed investigation and analysis can be found in Zhou (2001b; 2002)

1) Spatial resolution: Panchromatic imagery with 0.6 to $3 \mathrm{~m}$ resolution, multispectral imagery with $4 \mathrm{~m}$ resolution and hyperspectral imagery with $8 \mathrm{~m}$ resolution.

2) Swaths: 4 to $40 \mathrm{~km}$.

3) Spectral coverage: from 0.4 to $2.5 \mu \mathrm{m}$ with 200 channel, and $10 \mathrm{~nm}$ spectral resolution.

4) Revisit: Less than three days with the ability to turn from side-to-side on demand further decreasing the revisit interval.

5) Delivery time from acquisition to user: Imagery can be down-linked in real-time to ground stations located around the world.

6) Capability of stereo and multiangulatr systems: Alongtrack and cross-track stereoscopic capability using the linear array imaging principle. In particular, IKONOS and Quickbird satellites can offer rigid photogrammetric geometry for the high metric accuracies needed by mapping communities.

7) Sensor position and attitude: GPS and digital star trackers to maintain precise camera station position and attitude.

8) Imager type: Whisk-broom and push-broom imaging modes.

9) Owners: By 2005, ownership will include Argentina, Brazil, Canada China, France, Germany, India, Israel,
Japan, Korea (South), Portugal, Ukraine, AL and the United States (both government and commercial sectors).

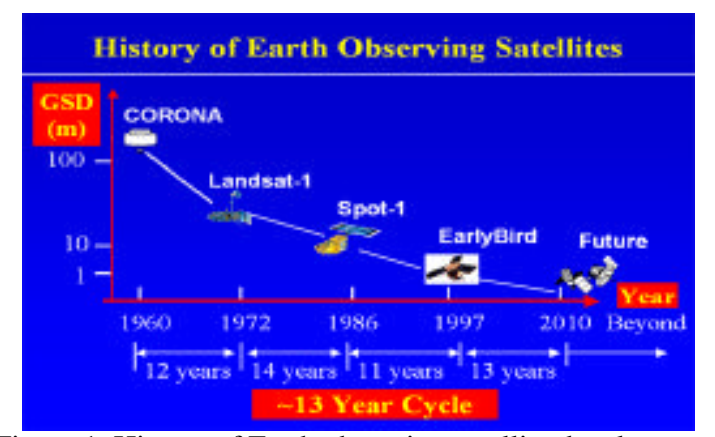

Figure 1. History of Earth observing satellite development

\subsection{What might be the Next Generation of Earth Observing Satellites?}

As shown in the review above, there has been a significant jump in EOS technology about every 10-15 years . Based on this, it is estimated that the current generation of satellites will be replaced by another generation around 2010 . What will be the characteristics of this NEXT generation of EO satellites?

We think the Earth observation satellite has passed the threshold of maturity as a commercial space activity. The next generation of satellites will be intelligent. The intelligent system we envision will be a space-based configuration for dynamic and comprehensive on-board integration of sensors, data processors and communication systems. It will enable simultaneous, global measurement and timely analysis of the Earth's environment for real-time, mobile, professional and common users in the remote sensing, photogrammetry, GIS, and broader user communities (Zhou, 2001b). This is because user's demands in the GIS, mapping, natural resources, environmental science, Earth monitoring, and applications communities have migrated from basic imagery to temporal, site specific, update mapping products and image-derived information. Data and information revisions will be requested more frequently; that is, in many ways analogous to today's weather updates. In addition, common consumers will be less concerned with the technical complexities of image processing, requiring imagery providers to use different strategies to provide users directly with valueadded images (e.g., orthorectification, feature enhancement, radiometric intensification, etc.) and value-added products (e.g., orthoimage mosaics) in order to meet real-time, mobile needs. This presents new challenges for the next generation of technology development. These challenges include, for example:

(1) Revisit cycle: Although the revisit cycle of current satellites can be as good as 1-3 days, and IKONOS achieves near real time data delivery to users worldwide with a 5-meter mobile antenna on a trailer, the real-time data collection requirements of most users cannot be met presently (e.g., emergency rescue, flood real-time monitor, ). Intelligent satellites will require a revisit cycle with hours or decade minutes base to meet various users' needs.

(2) Common users: Currently downlinked satellite "raw" data cannot serve common users directly because they do not know how to generate orthophotos for area measurement, how to generate an elevation model or how to classify imagery according to their needs without professional training and special software. Like today's maps, intelligent satellite images will serve a wide array of users. 
(3) Direct downlink for users: Traditionally, the process of providing data to a user involves: (1) transferring an original satellite signal to an intermediate frequency, (2) storing this frequency as 'raw' digital data, (3) converting the raw data to computer-readable data, and (4) archiving these data until a user orders the image. Future intelligent satellite images will be downloaded directly with a mobile device, such as a cell phone or laptop computer.

(4) Simple receiver facilities: Satellite receiving stations usually have to establish fixed facilities, such as large antennas. Future intelligent satellite images will be downlinked by mobile devices containing small antennas.

(5) Easy operating receiver: Traditionally, satellite receiving stations only carry out image receiving and archiving with little concern for how the images will be used. On the other hand, most non-professional users do not know how to order or use these images. As a result, many acquired images have been archived and may never be used. Future intelligent satellite images will be down-linked and used as easily as today's TV reception. Users will use a remote control to select a "channel" to get the images they want.

(6) On-board generation of value-added products: The current capability of on-board satellite data processing is still very low. Many products of satellite data are the result of post-processing, e.g., classified thematic maps. This situation limits their application largely because common users do not typically have the software or training to use it. The value-added products delivered by future intelligent satellites will be processed on-board via user commands.

\section{DESIGN OF INTELLIGENT SATELLITES}

\subsection{Concept Design}

Usually, space system design ignores user requirements, focusing instead on defining and specifying the satellite system (Campbell et al., 1998). In contrast, the principle of design for intelligent satellite systems is that users and their needs form the starting point. This is because more and more users want providers to deliver the value-added content they need, without having to be concerned about the technical complexities of image processing. Therefore, timely, reliable, and accurate information, with the capability of direct downlink of various bands of satellite data/information and operation as simple as selecting a TV channel, is highly preferred (Figure 2). Thereby, the FIEOS first will be designed conceptually without considering the complexity of technology, and then the feasibility and possibility of technologies are validated and the development phase and cost required to realize these concepts are estimated.

\begin{tabular}{|c|c|c|}
\hline \multicolumn{2}{|r|}{ Various Users } & Illustration \\
\hline $\begin{array}{l}\text { Mobile } \\
\text { user }\end{array}$ & $\begin{array}{l}\text { A real-time user, e.g., a } \\
\text { mobile GIS user, requires a } \\
\text { real-time downlink for geo- } \\
\text { referenced satellite imagery } \\
\text { with a portable receiver, } \\
\text { small antenna and laptop } \\
\text { computer. }\end{array}$ & \\
\hline $\begin{array}{c}\text { Real-time } \\
\text { user }\end{array}$ & $\begin{array}{l}\text { A mobile user, e.g., a } \\
\text { search-and-rescue pilot, } \\
\text { requires a real-time } \\
\text { downlink for geo- } \\
\text { referenced panchromatic or } \\
\text { multispectral imagery in a } \\
\text { helicopter. }\end{array}$ & \\
\hline Lay user & $\begin{array}{l}\text { A lay user, e.g., a farmer, } \\
\text { requires geo-referenced, } \\
\text { multispectral imagery at a } \\
\text { frequency of } 1-3 \text { days for } \\
\text { investigation of his harvest. }\end{array}$ & \\
\hline $\begin{array}{c}\text { Profession } \\
\text { al user }\end{array}$ & $\begin{array}{l}\text { A professional user, e.g., a } \\
\text { mineralogist, requires } \\
\text { hy perspectral imagery for } \\
\text { distinguishing different } \\
\text { minerals. }\end{array}$ & \\
\hline $\begin{array}{l}\text { Profession } \\
\text { al user }\end{array}$ & $\begin{array}{l}\text { A topographic } \\
\text { cartographer, e.g., a } \\
\text { photogrammetrist, requires } \\
\text { panchromatic images for } \\
\text { stereo mapping. }\end{array}$ & \\
\hline
\end{tabular}

Figure 2. Some examples of future direct end-users.

\subsection{Concept Architecture}

It is apparent that no single satellite can meet all of the requirements presented by users above. In addition, the past design of EO systems focused on placing numerous scientific instruments on relatively large and expensive space platforms (Prescott et al., 1999). This requires that the instruments, the spacecraft, and the space transport system have multiple redundant components that are built with expensive failureproof parts because of the risk of launch or in-orbit failure (Schetter et al., 2000; Campbell et al, 1999; and Zetocha, 2000). The design of future intelligent systems will overcome these drawbacks by using such features as a multi-layer satellite web with high-speed data communication (cross-link, uplink, and downlink), and multiple satellites with on-board data processing capability.

\subsubsection{Multi-layer satellite networks}

This satellite network consists of two layers. The first layer, which consists of hundreds of EO satellites viewing the entire Earth, is distributed in low orbits ranging from $300 \mathrm{~km}$ to beyond. Each EOS is small, lightweight and inexpensive relative to current satellites. These satellites are divided into groups called satellite groups. Each EOS is equipped with a different sensor for collection of different data and an on-board data processor that enables it to act autonomously, reacting to significant measurement events on and above the Earth. They work together collaboratively to conduct the range of functions currently performed by a few large satellites today. There is a lead satellite in each group, called group-lead; the other satellites are called member-satellites. The group-lead is responsible for management of the member-satellites and 
communication with other group-leaders in the network (constellation) in addition to communication with the geostationary satellites. This mode of operation is similar to an intranet. The group-lead looks like a local server, and the member-satellites look like the computer terminals. The local server (group-lead) is responsible for internet (external) communication in addition to management of the intranet (local) network.

This design can reduce the communication load and ensure effectiveness of management and coverage of data collection.

The second layer is composed of geostationary satellites because not all EOSs are in view of, or in communication with, worldwide users. The second layer satellite network is responsible for communication with end-users (e.g., data downlink) and ground control stations, and ground data processing centers, in addition to further processing of data from group-lead satellites.

All of the satellites are networked together into an organic measurement system with high speed optical and radio frequency links. User requests are routed to specific instruments maximizing the transfer of data to archive facilities on the ground and on the satellite (Prescott et al., 1999). Thus, all group-leads must establish and maintain a high-speed data cross-link with one another in addition to uplink with one or more geostationary satellites, which in turn maintain high-speed data cross-links and down-links with end users and ground control stations and processing centers.

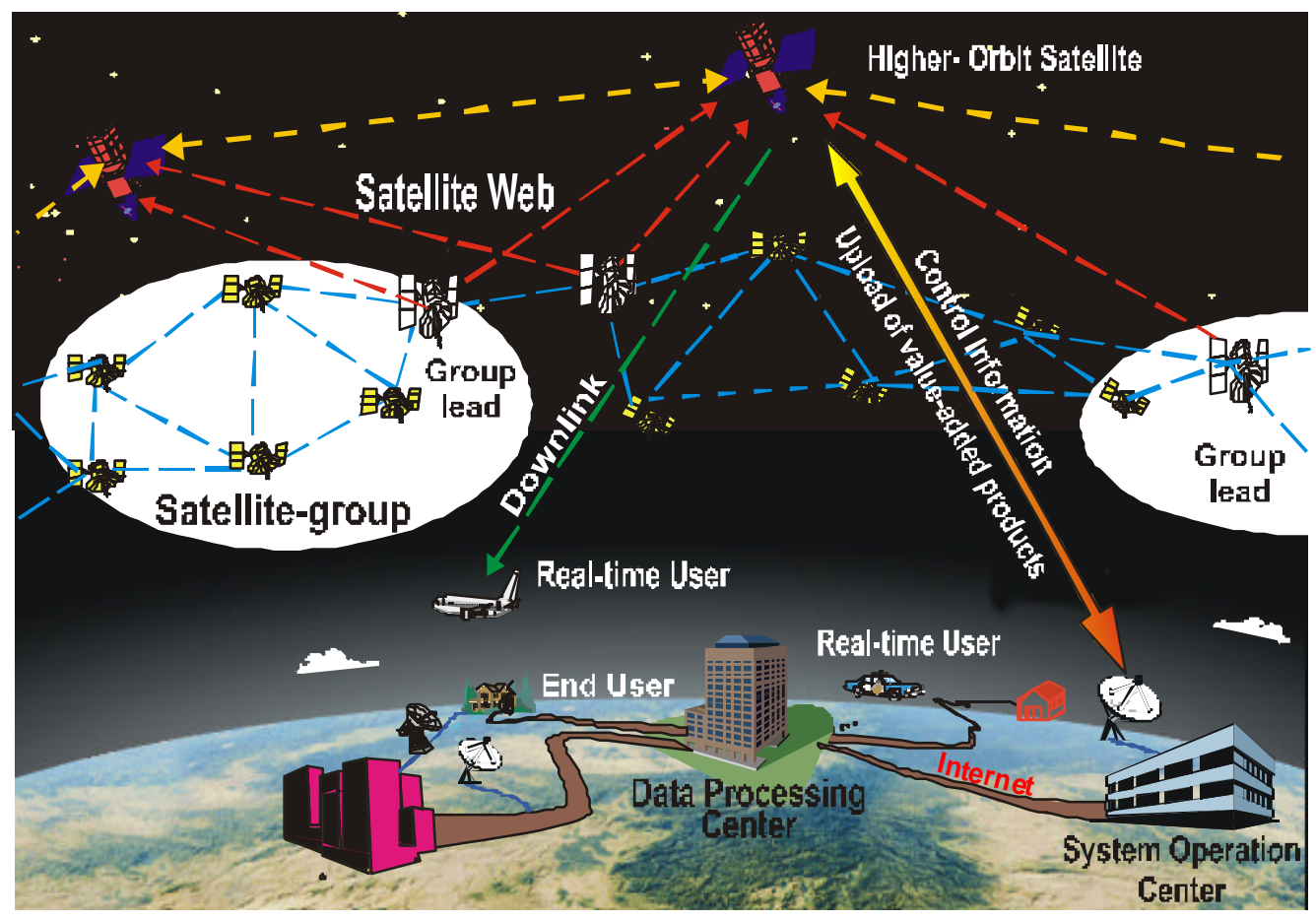

Figure 3. The architecture of a future intelligent Earth observing satellite system.

\subsubsection{Performance of satellite constellation}

The normal operating procedure is for each EOS to independently collect, analyze and interpret data using its own sensors and on-board processors. These collected data will not be transmitted to ground users, the ground station, or geostationary satellites unless they detect changed data. When an EOS detects an event, e.g., a forest fire, the sensing-satellite rotates its sensing system into position and alters its coverage area by adjusting its system parameters to bring the event into focus (Schoeberl et al., 2001). Meanwhile, the sensing-satellite informs member-satellites in its group, and the membersatellites adjust their sensors to acquire the event, resulting in a multi-angle, -sensor, -resolution and -spectral observation and analysis of the event. These data sets are merged to a geostationary satellite that assigns priority levels according to the changes detected. Following a progressive data compression, the data are then available for transmission to other geostationaries. The links between the geostationary satellites provide the worldwide real-time capability of the system. Meanwhile, the geostationary further processes the data to develop other products, e.g., predictions of fire extent after 5 days, weather influence on a fire, or pollution caused by a fire. These value-added products are then also transmitted to users.

If the geostationary cannot analyze and interpret the data, the "raw" data will be transmitted to the ground data processing center (GDPC). The GDPC will interpret these data according to user needs, and then upload the processed data back to the geostationary. In the constellition, all satellites can be independently controlled by either direct command from a user on the ground, or autonomously by the integrated satellitenetwork system itself.

The satellite transmits images in an order of priority, the more important parts of the data first. For example, the multi-spectral imagery of a forest fire may have higher priority than the panchromatic imagery. Panchromatic imagery for 3D mapping of a landslide may have priority over multispectral imagery, etc. Of course, the autonomous operation of the sensors, processors and prioritization algorithms can be subject to override by system controllers or authorized users. 
This concept of performance is similar to the sensor-web concept as envisioned by the Earth Science Vision Initiative, and Earth Science Vision Enterprise Strategic Plan of NASA. Here, we expand that concept with a detailed description of each of the FIEOS components.

\subsubsection{On-board data processing}

A crucial component for FIEOS is their on-board data processing capability. This capability should include: (1) image data processor, (2) data management processor, (3) data distributor, (4) resource management processor, (5) housekeeping functions, and (6) platform/sensor control.

Image Data Processor: Each EOS should have strong capabilities for on-board image processing, especially a change detection capability. This low-level of data processing should perform:

- Image filtering, enhancement, and radiometric balance,

- Data compression,

- Radiometric and geometric on-board correction of sensor signals,

- Geometric on-board correction of systematic alignment errors,

- Geometric on-board correction of spacecraft attitude,

- A thematic on-board classifier for disaster warning and monitoring, and

- Change detection so that only specified change data are transmitted.

A higher-level data processor is required for generation of value-added products that use robust algorithms and less human interaction. At present, this level of processing can be performed cost effectively only on the ground. The next generation of intelligent processors will be mounted on a geostationary satellite. A typical configuration might include:

- Prediction via specific models,

- Completely autonomous mission planning and scheduling,

- Completely autonomous housekeeping and data management,

- Completely autonomous sensor and platform control, and

- Autonomous resource management.

On-board Data Management: FIEOS will have enough functions to autonomously perform all conceivable manipulations of data to meet the various user's tasks on-board, e.g., data handling, data storage, data downlink, data distribution (distributor).

On-board Data Distributor: FIEOS will distribute data automatically and directly to different users upon their request without other human involvement and with minimum delay. The optimal downlink times should be uploaded in the form of a file from a ground control center or calculated on-board the geostationary satellites. The more important parts of the data are sent first, followed by the less important parts of the data.

On-board Housekeeping: FIEOS will be capable of all routine housekeeping tasks. For example, the satellites should autonomously manipulate, in the case of anomalies, failure detection, failure identification and first-level recovery actions, as well as software loading, unloading and management.

On-board Resources Management: FIEOS will be capable of autonomous management and assignment of power. Excess power and energy (above the basic spacecraft control requirements during daylight and eclipse phases (Teston et al., 1997) will be allocated to the instruments and to the spacecraft subsystems supporting the specific operations of the instruments. The allocation will be performed on a dynamic basis, resolving task constraints and priorities. Constraints include for each activity the power and data storage area needed, the pointing requested.

On-board Instrument Commanding: the typical instrument commands contain planning, scheduling, resource management, navigation, instrument pointing, and downlinks of the processed data.

On-board Platform Control: FIEOS platforms will be controlled intelligently and autonomously, including the followed aspects:

- Platforms adjust their positions in space relative to the constellation of sensors in response to collaborative data gathering,

- Autonomous operation of single satellite and satellite network, and

- Decision support and planning.

On-board Mission Planning and Scheduling: FIEOS will resolve the planning and scheduling of missions on-board using a combination of a constraints solver and optimizer to achieve the best possible mission data return. Ideally, complete autonomous mission planning will be executed on-board. When required, the on-ground and the OBMM (on-board mission manager) mission planning tools will be used for coordinating the schedule of activities, whose resulting schedule must be confirmed on-ground prior to its execution on-board.

\subsubsection{End-user operations}

End users expect to receive down-linked satellite data directly (in fact, the concept of data means image-based information, rather than traditional remotely sensed data) using their own receiving equipment. The overall operation appears to the endusers as simple and easy as selecting a TV channel by using a remote control (Figure 4). Therefore, three basic types of antennas and receivers are illustrated conceptually in Figure 4: (1) the hand-held antenna and receiver for real-time and mobile users, (2) the mobile antenna for mobile users, and (3) the fixed antenna for popular users, professional users or satellite receiving station, are conceptually designed (Figure 4). All receivers are capable of uploading the user's command, and mobile and hand-held receivers have GPS receivers installed, i.e., mobile user's position in geodetic coordinate system can be real-time determined and uploaded to geostationary satellite. The on-board data distributor will retrieve an image (block) from its database according to the user's position. 


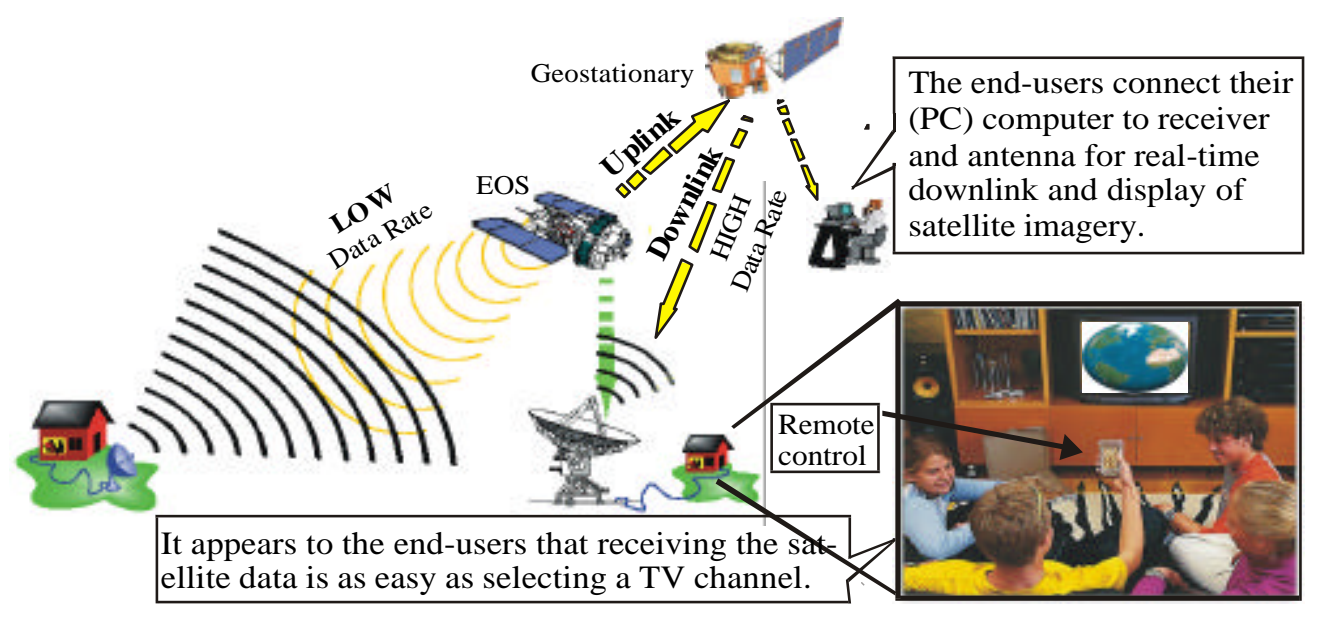

Figure 4. End-user operation like selecting a TV channel

In this fashion, an ordinary user on the street is able to use a handheld wireless device to downlink/access the image map of his surroundings from a geostationary satellite or from the Internet. Homes in the future are also able to obtain atmospheric data from the satellite network for monitoring their own environments. The intelligent satellite system will enable people not only to see their environment, but also to "shape" their physical surroundings. The downlinked data that users receive is not an actual image; instead, it receives a signal, much like a TV antenna receiving a TV signal, rather than direct picture and sound. This signal must be transformed into picture and sound in the TV set. Similarly, the FIEOS signal (which we call a special signal) is different absolutely from the signal of current EO satellites. Thus, FIEOS satellite signals must be transformed into an image by the users receiving equipment. Therefore, users need:

(1) User Software for Data Downlink: The special signal is transformed by software, which is provided by the ground control center so that real-time and common users can use it easily. For a lay user complicated application software is unnecessary because the user analyzes and interprets the images using their perceptual faculties. For more advanced users, advanced software will still be necessary because they use "imagery" in different ways.

(2) Accessible Frequency: Different users need different imagery, e.g., a photogrammetrist needs fore and aft stereo panchromatic imagery for stereo mapping; a biologist needs hyperspectral imagery for flower research. Thus, different types of satellite images are assigned with different broadcast frequencies, which the ground control station provides access to for authorized users.
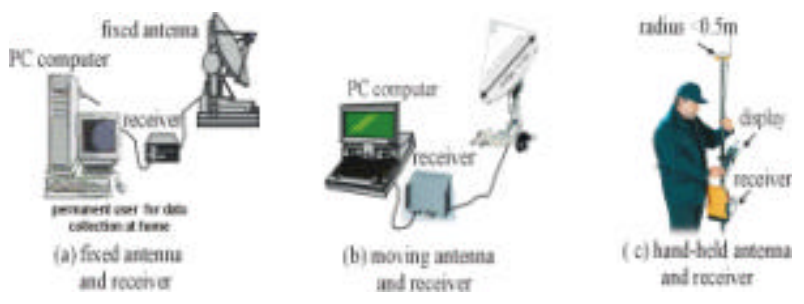

Figure 5. Concept design of antenna, receiver and end users in FIEOS.

\subsubsection{Ground control station}

The functions of the ground control station in FIEOS will decrease over time due to increasing satellite autonomy. In addition to some basic functions like (1) steering and monitoring satellite transmissions continuously, (2) predicting satellite ephemeredes, (3) calibrating the satellite flying parameters and navigation, (4) evaluating the satellite's performance, (5) monitoring the satellite's health and status, and (6) taking corrective measures in the event of detection of an on-board anomaly), the characteristics of the ground control station in FIEOS are:

- Upload of value-added product data to the geostationary satellites, and

- Communicate guidance about receiving frequency, software use, display, and so on to end-users.

\subsection{Characteristics of the Intelligent Earth Observing Satellite System}

The design concept for FIEOS is flexible because any additional satellites can easily be inserted without risk to the infrastructure, and the instruments and platforms are organically tied together with network information technology. The constellation (multilayer satellite network) insures that global data are collected on a frequency of decade minutes or shorter; event-driven data are collected with multi-angle, multi-resolution, multi-bands, and users can acquire images of any part of the globe in real-time. This design concept provides a plug-and-play approach to the development of new sensors, measurement platforms and information systems. The concept permits smaller, lighter, standardized satellites with independent functions to be designed for shorter operational lifetimes than today's large systems so that the instrument technology in space can be kept closer to the state-of-the-art.

FIEOS will perform much of the event detection and response processing that is presently performed by ground-based systems through use of high performance processing architectures and reconfigurable computing environments (Alkalai, 2001; Armbruster et al., 2000; Bergmann et al., 2000). FIEOS will act autonomously in controlling instruments and spacecraft, while also responding to specific user commands to measure specific events or features. So, users can select instrument parameters on demand and control on-board algorithms to preprocess data for information extraction. 


\subsection{High data rate transmission and high-speed network communication}

In the FIEOS constellation conceptualized here, satellites will be in different orbits, and their relative velocities will vary significantly. Hence, establishing and maintaining real-time network communication that includes high-speed data crosslink of EOSs, uplink of user/ground control station and geostationary, downlink of user and geostationary (see Figure 2), is NOT a simple problem (Surka et al., 2001; Welch et al., 1999). Obviously, the technology for high-speed wireless (optical or RF) data linking to connect satellite-to-satellite, and satellite-to-ground for high data rate transmission and the network management are vital elements for this concept.

\subsection{On-board data processing capabilities}

Success of on-board data processing is crucial to realize FIEOS. On-board data processing includes an image data processor, data distributor, data management processor, housekeeping, resource management, on-board command planning, platform/sensor control, and other elements. One of the essential capabilities provided by on-board processing is satellite autonomy (Prescott et al., 1999; Ramachendran et al., 1999). This autonomy requires mission operations and data processing/interpretation activities to evolve from ground-based control/analysis towards on-board control/analysis. The following is only a part of on-board data processing.

1. On-board Image Processing: Some image processing, such as image filtering, enhancement, compression, radiometric balance, edge detection and feature extraction, could be automatically processed on-board with techniques currently available or to be developed within the next 10 years. However, higher-level intelligent image processing, like classification, spatial information extraction, change detection, image interpretation, pattern recognition, and 3D reconstruction will need several generations of development. It has been demonstrated that full-automation of image analysis and image interpretation is quite difficult, particularly in complex areas such as wetlands and urban environments. In particular for FIEOS, the important function is its change detection capability, i.e., FIEOS only transmits those data that have been changed when compared with images stored on a database system.

2. Data Storage and Distribution: FIEOS requires huge data storage capabilities on-board and autonomous operation of data distribution; thus, some advanced and novel data handling technologies such as data compression, data mining, advanced database design, data and/or metadata structures will be required to support autonomous data handling (Caraveo et al., 1999).

3. On-Board Software: Real-time software systems for integrating all of the components of the satellite network and completing the flow of data from collection and transmission, to information extraction and distribution will be one of the key elements in FIEOS. Additionally, in order to produce value-added data products useful to common users, the current application software, algorithm, and dynamic searching will need to be improved. In order to downlink directly to common users, advanced concepts such as dynamic and wireless interaction technology will need to be designed for handling huge data computational requirements of dynamic interaction.

\section{CONCLUSIONS}

This report provides a high-level entry point for the design and architecture of an envisioned future intelligent Earth observing satellite system. The proposed system is a space-based architecture for dynamic and comprehensive on-board integration of EO sensors, data processors and communication systems. It is intended to enable simultaneous, global measurements and timely analyses of Earth's environments for a variety of users. The architecture and implementation strategies suggest a seamless integration of diverse components into a smart, adaptable, and robust EO satellite system.

The design concept envisions a system that uses instruments requiring technologies that provide Earth science measurements to a degree of precision and span of coverage not currently available. Common users would access data directly, and in a manner similar to selecting a TV channel. The imagery viewed would most likely be obtained directly from the satellite system. Real-time information systems are key to solving the challenges associated with this architecture. Realization of such a technologically complex system will require contributions of scientists and engineers from many disciplines. Hopefully, this revolutionary concept will impact dramatically how NASA develops and conducts missions in the next few decades.

As spatial information sciences mature, it is time to 'simplify' technologies so that more users can obtain information directly from satellites. The future is promising for the photogrammetry/remote sensing/GIS communities. A thorough feasibility study addressing the key technologies of each of the components, the necessity, possibilities, benefits and issues, and exploration of specific funding opportunities for implementation will be performed in Phase II.

\section{ACKNOWLEDGMENTS}

This project is funded by the NASA Institute of Advanced Concepts (NIAC) under contractor number NAS5-98051. Our warmest thanks go to Dr. Bob Cassanova, Dr. Paul Kauffmann, Dr. Oktay Baysal. We thank all the people who were kind enough to lend us their ears and eyes to discuss a number of topics crucial for completion of our work. We are grateful to those satellite development scientists who provide me with helpful advice, and relevant materials.

\section{REFERENCES}

Alkalai, L, 2001. An Overview of Flight Computer Technologies for Future NASA Space Exploration Missions, 3rd IAA Symposium on Small Satellites for Earth Observation, April 2 - 6, Berlin, Germany.

Armbruster, P. and W. Wijmans, 2000. Reconfigurable onboard payload data processing system developments at the ESA-presentation at SPIE 2000, Vol. 4132-12.

Bergmann, N.W. and A.S. Dawood, 2000. Reconfigurable Computers in Space: Problems, Solutions and Future Directions, The 2nd Annual Military and Aerospace Applications of Programmable Logic Devices (MAPLD'99) Conference, Laurel, Maryland, USA.

Bisnath S.B. and R.B. Langley, 2001. Precise Orbit Determination of Low Earth Orbiters with GPS Point Positioning. In proceedings of ION National Technical Meeting, January 22-24, 2001, Long Beach, CA. 
Campbell, M. and K. F. Böhringer, 1999. Intelligent Satellite Teams for Space Systems, 2nd Int. Conf. on Integrated Micro/Nanotechnology for Space Applications. Pasadena, California, April 11-15.

Caraveo, P. A., A. Bonati, L. Scandelli, U. Denskat, 1999. NGST On-Board Data Management Study, NGST Science and Technology Exposition, Hyannis, Massachusetts, USA, September 13-16.

Davis, C. O., D. Horan, M. Corson, 2000. On-orbit calibration of the Naval EarthMap Observer (NEMO) Coastal Ocean Imaging Spectrometer (COIS), Proceedings of SPIE, Vol. 4132.

Dawood, A. S. and N. W. Bergmann, 2001. The Second Generation of High Performance, Computing for Space Applications. Proceedings of The 3rd Annual Conference of the CRCSS, Newcastle, Australia, February.

Fritz, L. W., 1996. Commercial Earth Observation Satellites, Int Archives of Photogrammetry and Remote Sensing, Vol. XXXI, Part B4, Vienna, pp. 273-282.

Gill, E., O. Montenbruck, H. Kayal and K. Briess, 2001. Combined Space-Ground Autonomy for the BIRD Small Satellite Mission; IAA-B3-0505P; 3rd IAA Sym. on Small Sat. for Earth Observation, April 2-6, Berlin.

Lauer, D.T., S.A. Morain, and V.V. Salomonson, 1997, The Landsat Program: Its Origins, Evolution, and Impacts, Photogrammetric Engineering and Remote Sensing, 63(7):831-838.

Lillesand, T.M., and R.W. Kiefer, 2000. Remote Sensing and Image Interpretation, John Wiley \& Sons, Inc. 2000. ISBN: 0-471-25515-7. Fourth Edition.

McDonald, R.A., 1995. Opening the Cold War Sky to the Public: Declassifying Satellite Reconnaissance Imagery, PE\&RS, Vol. 61, No. 4, pp. $380-390$

Moreau, M., P. Axelrad, J. L. Garrison, D. Kelbel, 2000. GPS Receiver Architecture and Expected Performance for Autonomous GPS Navigation in Highly Eccentric Orbits. Navigation, Vol. 47, No. 3, pp. 191-204.

NASA, Earth Science Vision Initiative, http://staac.gsfc. nasa.gov/esv.htm.

NASA, The Earth Science Enterprise Strategic Plan. http://www.earth.nasa.gov/visions/stratplan/index. html.

NASA, NASA Space Technology, Instrument and Sensing Technology. http://ranier.hq.nasa.gov/Sensors _page/InstHP.html.

NASA, Landsate Satellites: Unique National Assets, at http://www.gsfc.nasa.gov/gsfc/service/gallery/fact_sheets/eart hsci/landsat/landsat7.htm

Prescott G., S. A. Smith and K. Moe, 1999. Real-Time Information System Technology Challenges for NASA's Earth Science Enterprise. The 1st International Workshop on Real-Time Mission-Critical Systems: Grand Challenge Problems. Nov. 30; Phoenix, Arizona.

Ramachandran, R., H.T. Conover, S.J. Graves, K. Keiser, C. Pearson and J. Rushing, 1999. A Next Generation Information System for Earth Science Data, The Int. Sym. on Optical Science, Eng. and Instrumentation, Denver.

Schetter, T., M. Campbell and D. Surka, 2000. Multiple AgentBased Autonomy for Satellite Constellations, 2000 ASA/MA Conference, September.

Schoeberl, M., J. Bristow and C. Raymond, 2001. Intelligent Distributed Spacecraft Infrastructure, Earth Science Enterprise Technology Planning Workshop, 23-24 January.

Stoney, W.E., 1996. The Pecora Legacy - Land Observation Satellites in the Next Century, in the Pecora 13 Symposium, Sioux Falls, South Dakota, August 22.

Surka, D.M., M.C. Brito and C.G. Harvey, 2001. Development of the Real-Time Object Agent Flight Software Architecture for Distributed Satellite Systems, IEEE Aerospace Conf., Piscataway, N.J.

Teston F., R. Creasey, and J. Bermyn and K. Mellab. 1997. PROBA: ESA's Autonomy and Technology Demonstration Mission, $48^{\text {th }}$ Int. Astronautic Congress.

Verduijn, F.F., T. Algra, G.J. Close, C. Lee, B.J. Denore, J.B. Williams, 2001. COCONUDS ? Two Years On, PRELIMINARY PROGRAM, 3rd IAA Symposium on Small Satellites for Earth Observation, April 2 - 6, Berlin, Germany.

Zetocha, P. 2000. Intelligent Agent Architecture for Onboard Executive Satellite Control, Intelligent Automation and Control, Vol. 9, TSI Press Series on Intelligent Automation and Soft Computing, Albuquerque, NM, pp. 27-32.

Zhou, G., 2001a. Architecture of Earth Observing Satellites in Next 10 Years and Beyond, ISPRS Joint Workshop on High Resolution Mapping from Space 2001, Sept 19-21, 2001. University of Hanover, Germany.

Zhou, G., 2001b. Earth Observing Satellites in Next 10 Years and Beyond, Technical Report to NASA/NIAC, Old Dominion University, December, 200

Zhou, G. et al., 2002. On-board geospatial database management in Earth Observing Satellites, First Int. Symposium on Future Intelligent Earth Observing Satellites, Nov. 10-15, Denver, Colorado.

Zhou, G. And K. Jezek, 2001a, 1960's Satellite Mosaic In Greenland, Int. J. of Remote Sensing, Vol. 26, No. 6, pp. 1143-1160.

Zhou. G. K. Jezek, 2001b. Orthorectifying 1960's Disclassified Intelligence Satellite Photography (DISP) of Greenland, IEEE Geoscience and Remote Sensing (in press).

Zhou G. and R. Li, 2000. Accuracy Evaluation of Ground Points from High-Resolution Satellite Imagery IKONOS, Photogrammetry Engineering \& Remote Sensing, Vol. 66. no. 9 , pp. $1103-1112$. 